\section{Ripening of Kiwifruit following Simulated Brushing with Commercial Brushes}

\author{
R. Massantini, L. Lanzarotta, R. Botondi, and F. Mencarelli ${ }^{1}$ \\ Istituto di Tecnologie Agro Alimentari Universita' degli Studi della Tuscia, \\ Via De Lellis, 01100 Viterbo, Italy
}

Additional index words. Actinidia deliciosa, ethylene, firmness, weight loss, softening

\begin{abstract}
Brushing of 'Hayward' kiwifruit [Actinidia deliciosa (A. Chev.) C.F. Liang et A. R. Ferguson var. deliciosa] to remove trichomes reduced their marketable life. Fruit were brushed with polypropylene brushes having bristles of $0.60,0.50,0.30$, and $0.25 \mathrm{~mm}$ in diameter. The two smallest-diameter bristles removed about $0.1 \mathrm{~g}$ of trichomes per fruit. The larger diameter bristles removed $12 \%$ more material, including some surface tissue particles. Brushing accelerated ripening during subsequent storage of fruit for $\mathbf{4}$ days at 4C as indicated by increases in ethylene production and soluble solid concentration and a decrease in firmness. The larger the bristle diameter, the greater the acceleration of ripening. The largest diameter did not accelerate ripening as much as $0.50-\mathrm{mm}$ bristles due to the lower resistance to bending $(0.85 \mathrm{~N}$ and $2 \mathrm{~N}$ for $0.60-$ and $0.50-\mathrm{mm}$ bristles, respectively) and their greater length. Small surface wounds, visible under the microscope, may have caused the higher ethylene evolution and the consequent ripening response.
\end{abstract}

As part of the overall postharvest cleaning process, fruit brushing usually is conducted to remove dirt and adhering particles; brush stiffness should be selected to remove dirt without causing injuries. Wet brushing with water spraying is most common; dry brushing is used on fruit and vegetables sensitive to wetting. Recently, kiwifruit in Italy have been brushed to remove surface trichomes, which appears to reduce consumer appeal. However, packinghouse supervisors have noted that brushing kiwifruit accelerates softening and shortens the storage life, causing problems in their subsequent distribution.

Trichomes on the fruit surface can trap water vapor and reduce the air velocity over the evaporating surface, thus decreasing the rate of water loss (Maxie, 1964). The breakage of epidermal hairs or trichomes in postharvest handling can aggravate water loss (Hoffman, 1967). Moreover, brushing pears (Pyrus communis L.) induces a rapid increase in ethylene evolution similar to that observed after wounding (Mencarelli and Botondi, 1991). Although kiwifruit produce little ethylene (often undetectable) at harvest, they are sensitive to exogenous ethylene (Sfakiotakis et al., 1989). Low levels of exogenous ethylene in the storage atmosphere can cause extensive softening (Arpaia et al., 1986; McDonald and Harman, 1982). Wound-induced ethylene also can initiate kiwifruit ripening (Hasegawa and Yano,

Received for publication 25 Oct. 1995. Accepted for publication 23 Jan. 1995. The cost of publishing this paper was defrayed in part by the payment of page charges. Under postal regulations, this paper therefore must be hereby marked advertisement solely to indicate this fact.

${ }^{1}$ To whom reprint requests should be addressed. Current address: Istituto di Industrie Agrarie, Universita' degli Studi di Pisa, via S. Michele 4, 56124 Pisa, Italy.
1990). Removing trichomes could produce small wounds that would stimulate ethylene production and trigger ripening. We investigated the effects of simulated brushing of kiwifruit with commercial brushes on ethylene evolution, soluble solids concentration (SSC), weight loss, and whole-fruit firmness changes.

\section{Materials and Methods}

General procedures. 'Hayward' kiwifruit were harvested in November at advanced maturity [SSC $=11.8 \%$ to $12.1 \%$, measured with a refractometer (Abbé, Officine Galileo, Florence, Italy); firmness monitored with an Instron universal testing machine (model 4301; Instron, Canton, Mass.) $=5.3$ to $5.4 \mathrm{~N} \cdot \mathrm{mm}^{-1}$, corresponding to $\approx 39 \mathrm{~N}$ monitored with $\mathrm{a}$ penetrometer (EFFEGI, Gaiarine, Ravenna, Italy) with an 8-mm tip after removing the peel] from a farm close to Rome. Uniformly sized (100 to $110 \mathrm{~g}$ ) and shaped fruit were selected. Any injured or misshapen fruit were discarded. Fruit were returned to the laboratory within $2 \mathrm{~h}$ of harvest and were subjected to brushing using commercial, polypropylene, linear bristle brushes (Fig. 1) provided by Tecnospazzole Spa, Bologna, Italy. The brush manufacturer provided the bristle diameter and bristle length (Table 1). We measured the density and the bristles' resistance to bending (Table 1). Density was evaluated by inserting a metal ring $\left(20 \mathrm{~mm}^{2}\right.$ surface $)$ from the top of the brush bristles to the bottom (metal support of the brush bristles) and counting the bristles enclosed by the ring. We took three measurements for each brush. The brushes' resistance to bending (i.e., bunches of bristles that constitute a brush) was measured with the universal testing machine adapted with a flat compression anvil ( $55 \mathrm{~mm}$ in diameter) that was driven at $10 \mathrm{~mm} \cdot \mathrm{min}^{-1}$. We adopted the arrangement used for the bending test, such as a cantilever, where the beam is clamped at one end and loaded at the other (Voisey and deMan, 1979). The metal base of the brushes were clamped tightly to a support, allowing the bristles to be moved freely, and the bristles were placed horizontal and orthogonal to the movement of the crosshead bar. The run of the bar was fixed to $10 \mathrm{~mm}$ (starting from the contact point between bristles and the anvil), and the applied force to deflect $10 \mathrm{~mm}$ of the horizontally placed bristles was recorded. Data are expressed in newtons as resistance to bending (Larmond, 1979).

Brushing test. The simulated brushing test was performed by two brushes (each $300 \mathrm{~mm}$ long) tightly clamped to a metal bar $(15 \mathrm{~mm}$ in diameter) that was rotated by a variable speed motor. Eight fruit were placed inside a stainless steel cylinder $(300 \mathrm{~mm}$ in diameter and $600 \mathrm{~mm}$ long) that was closed at one end; the working surface was kept horizontal (Fig. 2). One end of the metal brush bar was inserted in a hole drilled in the sealed end of the cylinder, and the other was inserted through another plate connected to the motor. To accommodate different lengths of brush bristles, four holes were drilled in the plates to allow just the tip of the bristles to brush the fruit surface and rotate the fruit. At the end of the test, fruit trichomes were collected from the cylinder and weighed. Preliminary tests indicated that the best rotation speed and duration to remove trichomes without excessive shaking of the fruit was 100 to $120 \mathrm{rpm}$ for $60 \mathrm{sec}$. After brushing, fruit were placed in open glass jars and stored at $4 \mathrm{C}( \pm 0.5 \mathrm{C})$ and $85 \%( \pm 5 \%)$ relative humidity in a $20-\mathrm{m}^{3}$ chamber. The low ratio between the weight of kiwifruit in the jars $(\approx 5 \mathrm{~kg}$ each replication) and the large free volume of the cold chamber, which was ventilated by fans, resulted in undetectable levels of ethylene in the cold room. This procedure avoided ethylene contamination from the various treatments, also considering the low ethylene production by kiwifruit. Weight loss, firmness, and ethylene evolution were followed for 4 days; SSC was measured at the beginning and the end of the test.

Fruit evaluation. Eight-fruit lots per each of five replications were weighed soon after the test and during the 4 days of storage at $4 \mathrm{C}$. Weight loss was expressed as the change in weight between brushing and examination of fruit after storage. To reduce the effect of fruit variability and to simulate the subjective firmness evaluation by consumers, whole-fruit firmness was monitored by using a deformation test under nondestructive force (Voisey and deMan, 1979), as used on whole tomato (Lycopersicon esculentum Mill.) by Hamson (1952) and Bourne (1967). The eight fruit used for the weight loss test were placed widthwise over the plate of the universal testing machine and compressed with a flat compression anvil (55 $\mathrm{mm}$ in diameter) at a rate of $20 \mathrm{~mm} \cdot \mathrm{min}^{-1}$ ( chart speed $=250 \mathrm{~mm} \cdot \mathrm{min}^{-1}$ ). The deformation of whole fruit to a load of $3 \mathrm{~N}$ (full scale range $=50 \mathrm{~N}$ ) was recorded. Instead of using the term "deformation to $3 \mathrm{~N}$ " (Bourne, 1982), we expressed data in terms of firmness (force/ 

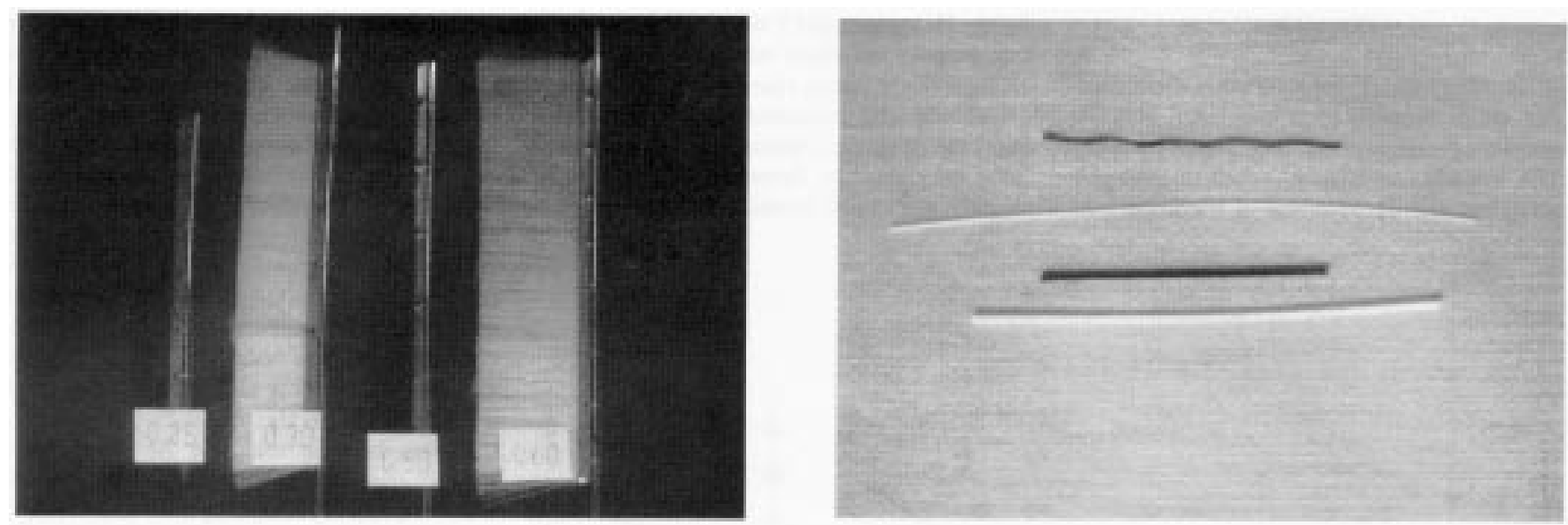

Fig. 1. (a) The commercial brushes used in the kiwifruit brushing test; (b) individual polypropylene bristle.

deformation to $3 \mathrm{~N}$ ) in newtons per millimeter (Olorunda and Tung, 1985). A preliminary test, with different loads, showed that $3 \mathrm{~N}$ did not induce tissue injury under the peel and allowed the same fruit to be used for the following 4 days. SSC of four fruit of each replication was measured with a refractometer at the beginning and end of the test.

Ethylene production. Ethylene evolution from kiwifruit was measured by removing 2 $\mathrm{ml}$ of the head space atmosphere of a 1000-ml glass jar sealed for $1 \mathrm{~h}$ and injecting the sample into a Fractovap (model 4200; Carlo Erba Spa, Milano, Italy) with 1-m-long alumina column (80/100 mesh) and a flame ionization detector (Carlo Erba Spa).

Injury detection. Microscopic examination was performed on brushed fruit by pouring a few drops of $12 \%(\mathrm{w} / \mathrm{w}) \mathrm{H}_{2} \mathrm{O}_{2}$ solution over the surface and placing the fruit below the microscope lens to observe whether bubbling occurred. Unbrushed fruit were treated in the same way. To confirm the effect of $\mathrm{H}_{2} \mathrm{O}_{2}$ over the wounds, we manually brushed the fruit superficially on one side and then poured $\mathrm{H}_{2} \mathrm{O}_{2}$ over the brushed and unbrushed side.

Statistical analysis. Data were tested by analysis of variance using MSTAT-C software.

\section{Results}

Brushes with 0.60- or 0.50-mm-diameter bristles removed a larger amount of epidermis materials (1.1 to $1.2 \mathrm{~g}$ from eight fruit) than 0.30 - or 0.25 -mm brushes ( 0.8 to $0.9 \mathrm{~g}$ ). In the former, this material was represented by trichomes and peel particles. Kiwifruit surfaces were smooth after brushing, regardless of the kind of brushes used. The larger the bristle diameter, the higher the weight loss (on the 4th day, $r=0.77$; weight loss $=0.659 \times$ diameter $+1.08 ; \mathrm{n}=20$ ), and it increased with time following brushing (Fig. 3). There was no difference among the control and $0.25-\mathrm{mm}$ brushes and among $0.30-, 0.50-$, and $0.60-\mathrm{mm}$ brushes on the second day. Subsequently, the latter two brushes induced higher weight loss; the difference between these two was nonsignificant.
Firmness declined as the bristle diameter increased (on the 4th day, $r=-0.97$; firmness $=-1.00 \times$ diameter $+4.89 ; \mathrm{n}=64)$ and with time following brushing (Fig. 4). Fruit brushed with $0.50-\mathrm{mm}$ brushes lost firmness more quickly than fruit brushed with $0.60-\mathrm{mm}$ brushes. However, fruit from both of these treatments were subjectively judged softer than fruit brushed with smaller-diameter bristles or the unbrushed control.

The pattern of weight loss and the firmness decrease, with increasing differences among the samples with time, suggested the potential involvement of wound ethylene and its autocatalytic production. Ethylene production showed an initial burst within $10 \mathrm{~h}$ following brushing. The height and the amplitude of this peak varied with the sample and might be due to a change in gas diffusion characteristics from the fruit after trichome removal. Analogous results by Yang and Pratt (1978) referred to tissue slices but may be applicable to injury caused by brushing. Following the initial early peak, ethylene production declined to a low level (between 3.5 and $8.0 \mathrm{nl} \cdot \mathrm{kg}^{-1} \cdot \mathrm{h}^{-1}$ ) until the end of test (Fig. 5). Fruit brushed with the 0.50 -mm-diameter bristles maintained the highest ethylene production, which increased starting $52 \mathrm{~h}$ after brushing. Fruit brushed with $0.60-\mathrm{mm}$ bristles produced a small amount of ethylene between 26 and $68 \mathrm{~h}$ but then increased, reaching the same ethylene production level as fruit brushed with the $0.50-\mathrm{mm}$ brush, which was 5 to 6 times the value for the unbrushed control fruit. The control always produced the least ethylene. The initial de-

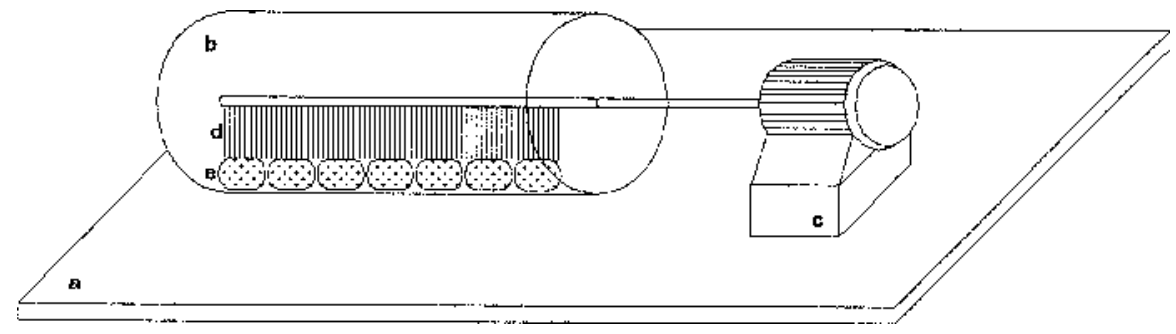

Fig. 2. Schematic drawing of apparatus used for brushing kiwifruit. $a=$ working surface; $b=$ stainless steel cylinder; $\mathrm{c}=$ variable speed motor; $\mathrm{d}=$ brush; $\mathrm{e}=$ kiwifruit. crease in ethylene evolution of unbrushed fruit was due to the acclimatation to the low storage temperature.

At the end of the test, SSC was $1.7 \%$ and $1.5 \%$ (higher) in fruit brushed with 0.50 - and 0.60 -mm bristles than for the control $(12.1 \%$ vs. $13.8 \%$ and $13.6 \%$, respectively). The increase was less pronounced in fruit brushed with the smaller-diameter bristles, with the control fruit increasing only $0.2 \%$ (data not shown).

Hydrogen peroxide applied on wounded tissue produced an intense bubbling (Fig. 6), presumably because of the presence of catalase. Bubbling was absent in noninjured tissue. Microscopic evaluation of the fruit surface revealed that the removal of trichomes also pulled off trichome base tissue when the $0.50-\mathrm{mm}$ and $0.60-\mathrm{mm}$ bristles were used.

Table 1. Characteristics of brushes used for brushing test of kiwifruit. Data are the mean of three readings each brush \pm SD.

\begin{tabular}{lccc}
\hline $\begin{array}{l}\text { Bristle } \\
\text { diam } \\
(\mathrm{mm})\end{array}$ & $\begin{array}{c}\text { Bristle } \\
\text { length } \\
(\mathrm{mm})\end{array}$ & $\begin{array}{c}\text { Density } \\
\text { (bristles/ }^{\mathrm{z}}\end{array}$ & $\begin{array}{c}\text { Resistance } \\
\text { to bending } \\
(\mathrm{mm})\end{array}$ \\
\hline 0.60 & 100 & $37 \pm 6$ & $0.85 \pm 0.06$ \\
0.50 & 40 & $60 \pm 8$ & $2.00 \pm 0.11$ \\
0.30 & 50 & $143 \pm 13$ & $0.75 \pm 0.08$ \\
0.25 & 30 & $163 \pm 10$ & $1.25 \pm 0.12$
\end{tabular}

${ }^{2}$ Density was measured by inserting a metal ring (20 $\mathrm{mm}^{2}$ of surface) from the top of brush bristles to the bottom (metal support of bristles) and counting the number of bristles closed inside the ring.

${ }^{y}$ Resistance to bending $=$ resistance to bristle deflection of $10 \mathrm{~mm}$. 


\section{Discussion}

Brushing was detrimental to kiwifruit, causing small wounds that triggered woundethylene production and accelerated ripening. The wounds consisted of small microscopic scratches and the removal of trichome base

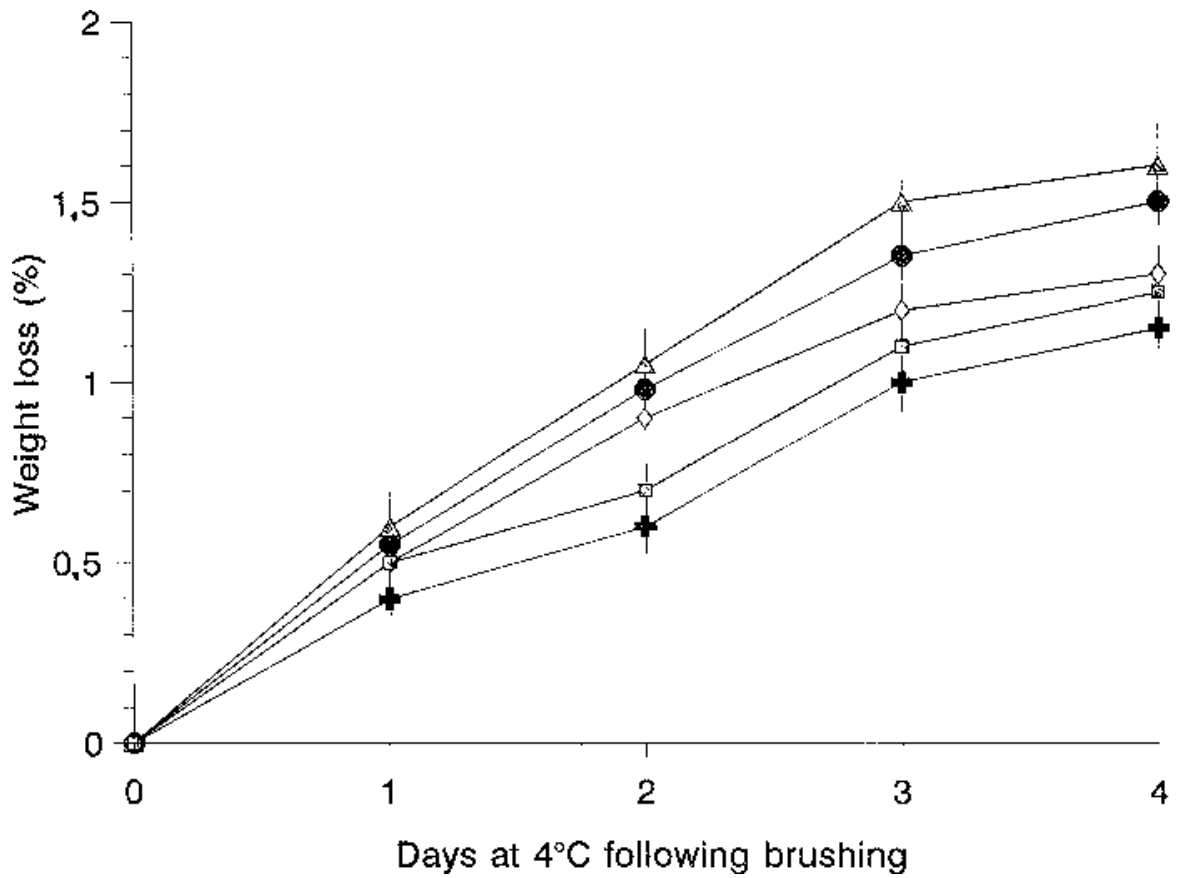

Fig. 3. Weight loss from brushed kiwifruit kept at $4 \mathrm{C}$ for 4 days. Each value is the mean of five replications (a lot of eight fruit each), vertical bars \pm SD. Bristle diameter (in millimeters): $0.25=\square ; 0.30=\diamond ; 0.50$ $=\Delta ; 0.60=$ octagon; control $=\mathbf{+}$.

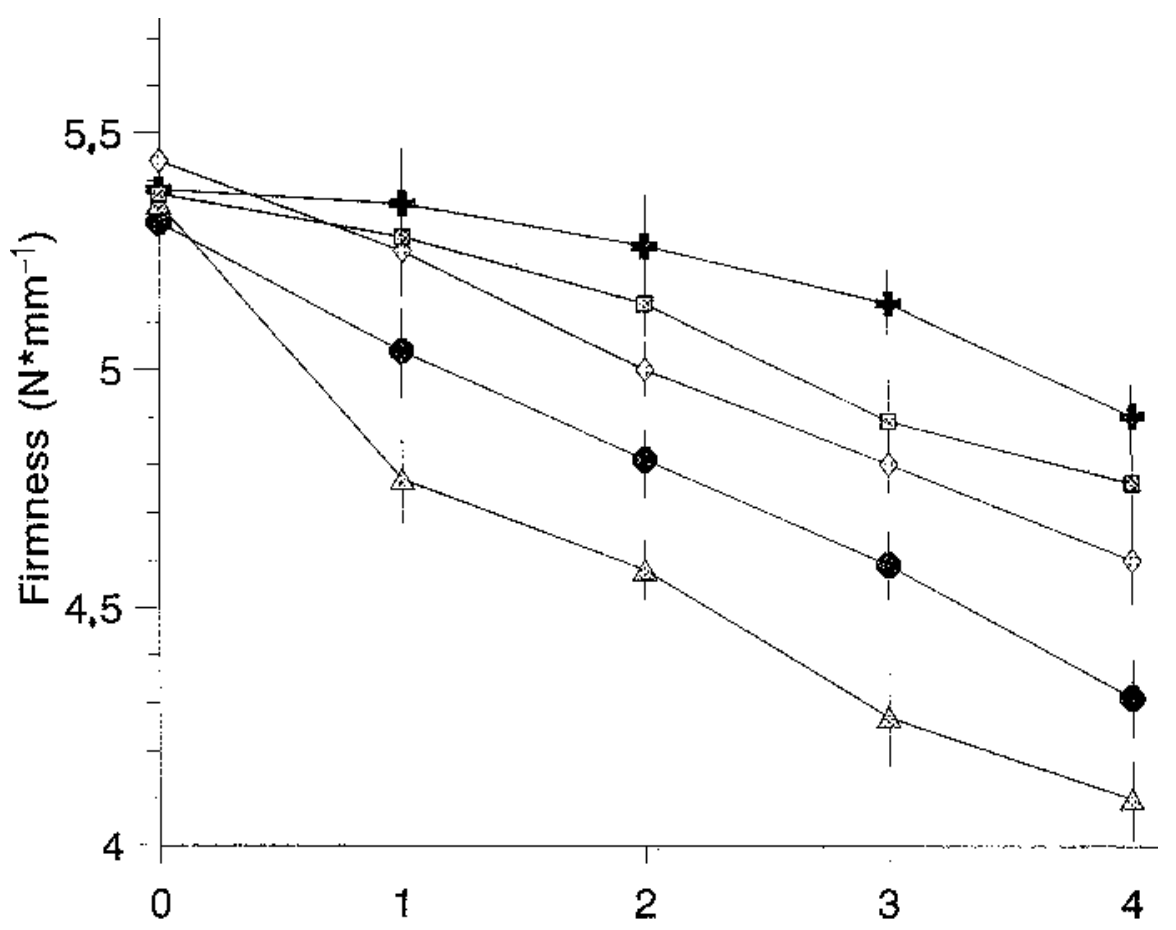

Days at $4^{\circ} \mathrm{C}$ following brushing

Fig. 4. Decline in firmness of brushed kiwifruit kept at $4 \mathrm{C}$ for 4 days. Each value is the mean of five replications of eight fruit each (40 fruit), vertical bars \pm SD. Bristle diameter (in millimeters): $0.25=\square$; $0.30=\diamond ; 0.50=\Delta ; 0.60=$ octagon; control $=\boldsymbol{+}$. during 4 days at $4 \mathrm{C}$. Fruit brushed with 0.25 or 0.30 -mm bristles initially produced more ethylene than fruit brushed with $0.60-\mathrm{mm}$ bristles. We attribute this difference to the rapid escape of ethylene from the fruit surface due to the relatively many trichomes removed by the many fine bristles, which presumably was in proportion to the density of brush bristles rather than to the severity of the wound response. The 0.50 -mm brushes have a bristle density intermediate between the 0.25 - to 0.30 $\mathrm{mm}$ and $0.60-\mathrm{mm}$ brushes, but their higher resistance to bending ( 2.0 vs. $1.25,0.85$, and $0.75 \mathrm{~N}$, respectively, for $0.25-, 0.60-$, and $0.30-\mathrm{mm}$ bristles) removed the base of trichomes, causing deep wounds. A similar effect was probably caused by 0.60 -mm bristles, but the lower bristle density coupled with the bristles' low resistance to bending may have resulted in fewer injuries than the $0.50-\mathrm{mm}$ bristles. The increase in ethylene production after $\approx 3$ days in fruit brushed with 0.50 - or 0.60 -mm bristles likely coincided with the final ripening response (Hyodo and Fukasawa, 1985 ) as a consequence of autocatalytic ethylene production.

\section{Conclusions}

Our results are related to using commercial brushes for brushing kiwifruit. We measured the density and the resistance to bending to better define the brushes, but we did not assess these two variables separately. Nevertheless, these characteristics jointly differentiated the effects of brush characteristics in terms of their likely commercial use for kiwifruit. Brushes with thin bristles ( 0.25 to $0.30 \mathrm{~mm}$ in diameter), low density, and, above all, short bristle length affected the resistance to bending ( 0.75 vs. $1.25 \mathrm{~N}$ for 0.30 - and $0.25-\mathrm{mm}$ bristles, respectively) and fruit ethylene evolution $(0.25>0.30 \mathrm{~mm})$ likely due to a greater removal of trichomes. Brushes with largerdiameter bristles $(0.50$ to $0.60 \mathrm{~mm}$ ) should not be used for brushing kiwifruit because they induce superficial injuries. Attention has to be paid to brush characteristics, above all to the bristles' resistance to bending because this factor seems to be highly correlated with the product of bristle diameter, length, and density $(r=-0.84)$, which could be considered as a cumulative index for the choice of brushes.

\section{Literature Cited}

Arpaia, M.L., F.G. Mitchell, A.A. Kader, and G. Mayer. 1986. Ethylene and temperature effects on softening and white core inclusions of kiwifruit stored in air or controlled atmospheres. J. Amer. Soc. Hort. Sci. 111:149-153.

Bourne, M.C. 1967. Deformation testing of foods. 1. A precise technique for performing the deformation test. J. Food Sci. 32:601-605.

Bourne, M.C. 1982. Effect of temperature on firmness of raw fruits and vegetables. J. Food Sci. 47:440-444.

Hamson, A.R. 1952. Measuring firmness of tomatoes in a breeding program. Proc. Amer. Soc. Hort. Sci. 54:272-276.

Hasegawa, Y. and Y. Yano 1990. Ripening and ethylene production in kiwifruit. Proc. XXIII 


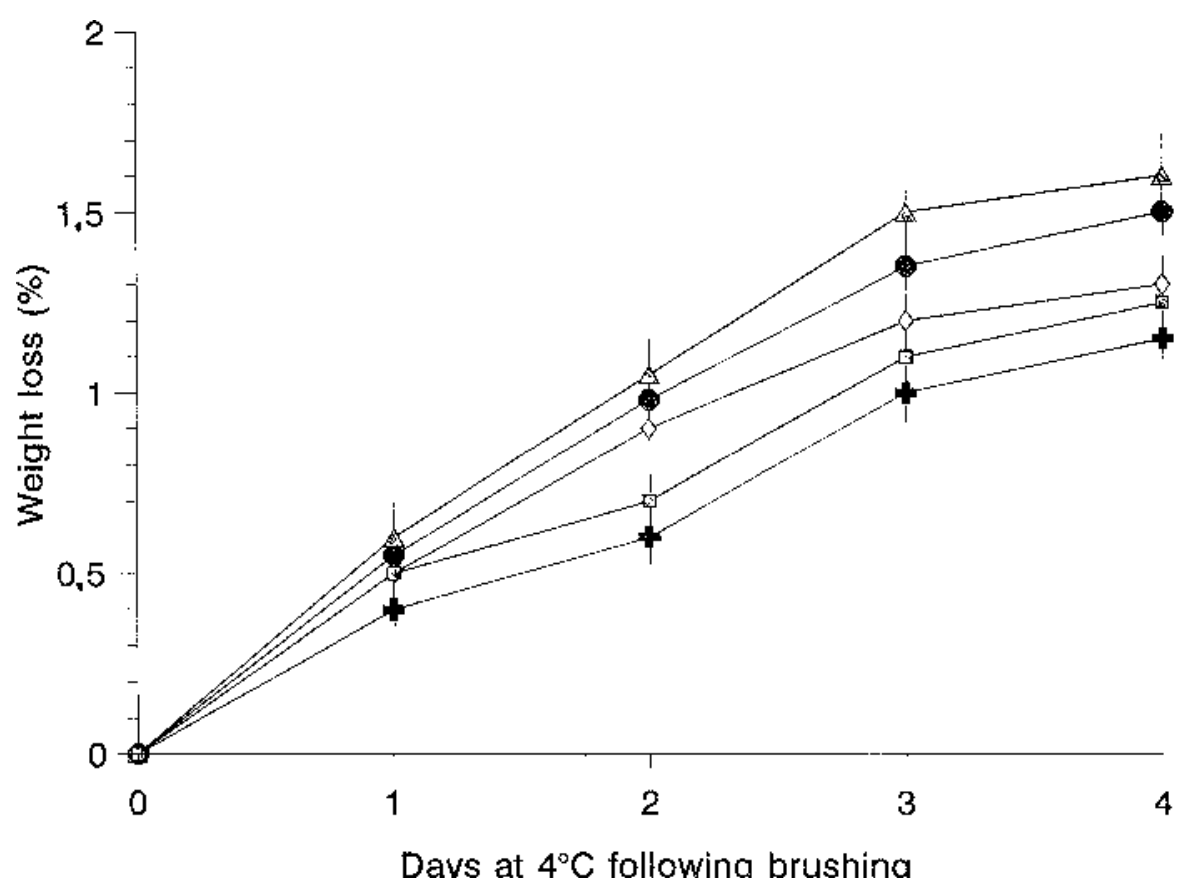

Fig. 5. Ethylene evolution from brushed kiwifruit kept at $4 \mathrm{C}$ for 4 days. Each value is the mean of the readings of three jars, each containing eight fruit, vertical bars \pm SD. Bristle diameter (in millimeters): $0.25=\square$; $0.30=\diamond ; 0.50=\Delta ; 0.60=$ octagon; unbrushed control $=\mathbf{+}$.

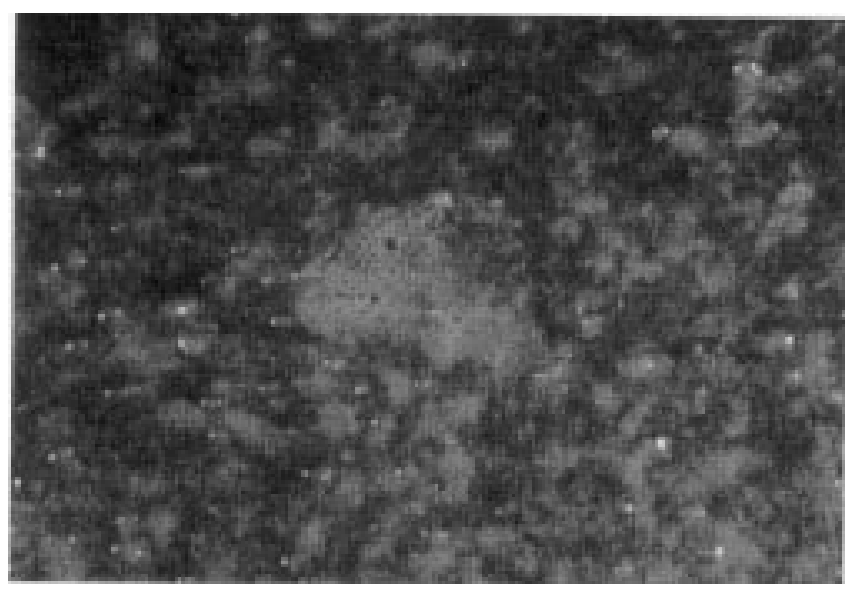

Fig. 6. Intense bubbling after $\mathrm{H}_{2} \mathrm{O}_{2}$ application, revealing the presence of wounds on brushed kiwifruit surface.
Intl. Hort. Cong., Florence, Italy, 27 Aug.-1 Sept. 1990. (Abstr. 3311)

Hoffman, J.C. 1967. Morphological variations of snap bean pods associated with weight loss and wilting. Proc. Amer. Soc. Hort. Sci. 91:294303.

Hyodo, H. and R. Fukasawa. 1985. Ethylene production in kiwi fruit. J. Jpn. Soc. Hort. Sci. 54:209-215.

Larmond, E. 1979. Sensory measurement of food texture, p. 535-545. In: J.M. deMan, P.W. Voisey, V.F. Rasper, and D.W. Stanley (eds.). Rheology and texture in food quality. AVI, Westport, Conn

Maxie, E.C. 1964. Effect of fruit structure and temperature on water loss. Proc. Fruit and Veg. Perishables Handling Conf., Univ. of California, Davis, p. 63-64.

McDonald, B. and J.E. Harman. 1982. Controlled atmosphere storage of kiwifruit. I. Effect on fruit firmness and storage life. Scientia Hort. 17:113-123.

Mencarelli, F. and R. Botondi. 1992. Effetti di abrasioni superficiali simulanti la pratica della spazzolatura sulla produzione di etilene da frutti di pera. Rivista di Frutticoltura 7-8:69-71.

Olorunda, A.O. and M.A. Tung. 1985. Simulated transit studies on tomatoes; Effects of compressive load, container, vibration and maturity on mechanical damage. J. Food Technol. 20:669678.

Sfakiotakis, E.P., G. Ververidis, and G. Stavroulakis. 1989. The control of autocatalytic ethylene production and ripening in kiwifruit by temperature and controlled atmosphere storage. Acta Hort. 258:115-116.

Voisey, P.W. and J.M. deMan. 1979. Application of instruments for measuring food texture, p. 142243. In: J.M. deMan, P.W. Voisey, V.F. Rasper, and D.W. Stanley (eds.). Rheology and texture in food quality. AVI, Westport, Conn.

Yang, S.F. and H.K. Pratt. 1978. The physiology of ethylene in wounded plant tissues, p. 595-622. In: G. Kahl (ed.). Biochemistry of wounded plant tissues. Walter de Gruyter \& Co., Berlin. 